\title{
Damage initiation and growth in laminated polymer compsosite plates with fluid-structure interaction under impact loading
}

\author{
Y. W. Kwon* and M. A. Violette \\ Dept. of Mechanical \& Aerospace Engineering \\ Naval Postgraduate School \\ Monterey, CA 93943, USA
}

\begin{abstract}
Damage initiation and growth as well as dynamic response of laminated polymer composite plates were investigated with the effect of FluidStructure Interaction (FSI) when they were subjected to impact loading. The E-glass composite plates were clamped along the boundaries and impact loading was applied from a specially designed vertical drop-impact testing machine while the plates were surrounded by either water or air. The damage and transient responses such as force- and strain-time history were measured during the progressive impact tests, and the test data collected from either impact in air or under water were compared to determine the effect of FSI. The study showed that FSI was generally detrimental to composite plates because of the hydrodynamic mass effect so that damage occurred at a lower impact force for the composite plate submerged in water. The strain measure also suggested that the FSI effect varied from location to location of the plate surface. Additionally, the FSI effect yielded a significant change in the strain response in terms of both magnitude and shape in time history for the plate in water along with progressive damage. In summary, it is essential to include the FSI effect for design and analysis of composite structures when they are in contact with water.
\end{abstract}

Keywords: Fluid-Structure Interaction (FSI), Polymer Composite, Damage Initiation and Growth, Impact Load

\section{INTRODUCTION}

Polymer composite materials have been used increasingly to structural components in both commercial and military applications. When specific strength and stiffness are major concerns, polymer composite materials have been common choices. For example, there has been growing use of composites in ship masts, superstructures, deck grates, piping, ducting, rudders, propellers, stacks, and various submarine structures [1].

Shock and impact are common dynamic loading to structures. As a result, polymer composite structures have been studied for such dynamic loading to understand their structural integrity and damage process. Most intensive studies have been conducted for lowvelocity impact damage in composite structures. Since there are so many publications in the subject area, several of them are just listed in the reference [2-6].

${ }^{*}$ Corresponding author E-mail: ywkwon@nps.edu 
When any structure is in dynamic motion in a fluid medium, there is, so called, FluidStructure Interaction (FSI). Depending on the ratio of the density of the structural material to that of the fluid medium, FSI may be strong or weak. In the case of combination of polymer composites and water, the FSI effect is quite important because both materials have very comparable densities. Most of the FSI studies investigated the natural frequency of beam or plates under water [7-10]. Besides, the majority of dynamic loading studies on composites did not consider the FSI effect. Some more recent works investigated the transient dynamic response of composites submerged in water [11-14].

A previous study $[11,13]$ showed, from both experimental and numerical results, that the impact force resulting from the same impact loading condition was much larger when the carbon-fiber composite plate was under the water than in air. The test was conducted without causing damage to the composite plate so that the dynamics response without failure could be compared between the submerged and dry structures. The greater impact force on the submerged plate was due to an added mass effect, since the carbon-fiber composite plate has a slightly higher density than the water.

The objective of this study is to investigate the transient dynamic response of as well as damage initiation and growth in laminated E-glass composite plates with FSI as the structures are subjected to progressively higher impact load. The study compares the results under the same impact loading when the structures are in air or submerged in water so as to examine the FSI effect on the composite structures. The following sections describe composite specimen preparation, impact testing under water and in air, their results and discussion, and conclusions.

\section{SPECIMEN FABRICATION AND TESTING}

The composite test plates were constructed to match, as closely as possible, the industry standard used in today's marine construction. The test plates were constructed using a Vacuum Assisted Resin Transfer Molding (VARTM) process as sketched in Fig. 1. Each composite consists of twelve layers of non-biased, plain weave 6 oz E-glass laid at 0/90 degree orientation. The reason E-glass was selected was that it is translucent so that delamination damage occurring from the tests can be detected visually. Otherwise, the test plate should be removed from the impact testing machine, described later, after every impact loading to check the damage state using any nondestructive testing technique. Then, the same plate should be attached to the impact machine again for the next stage of

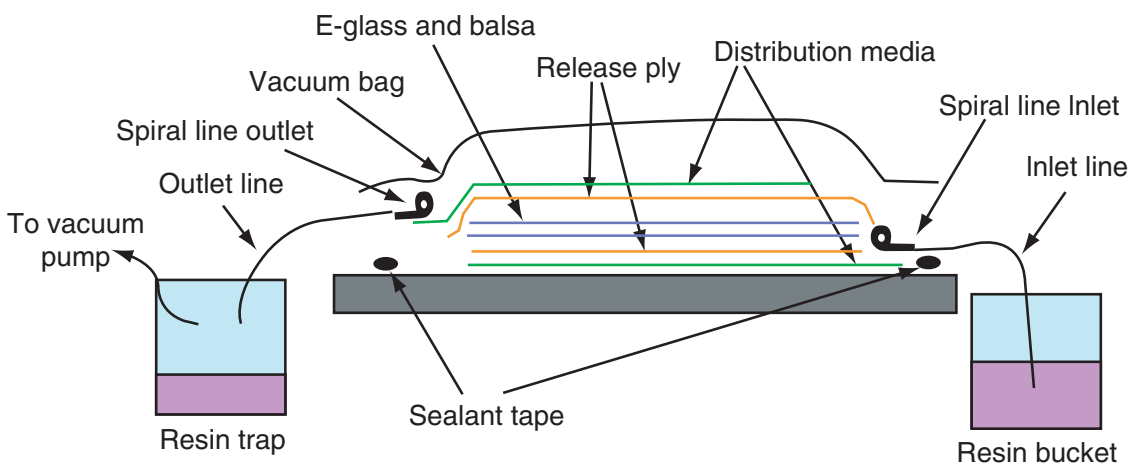

Figure 1 Schematic drawing of VARTM process. 
the impact testing to investigate progressive damage. Such a procedure is very cumbersome and can induce additional error when the plate was removed and reinstalled repeatedly.

The binding material was Derakane 510A vinyl ester resin with chemical hardeners, Methyl Ethyl Ketone Peroxide (MEKP), Cobalt Naphthenate (CoNap), and Ndimthylaniline (DMA). The hardeners were used as hardening and accelerating agents, with amounts varied to achieve the desired gel time of 45 minutes. Normal ambient temperature in the lab remained between $17^{\circ} \mathrm{C}$ and $20^{\circ} \mathrm{C}$. To achieve a gel time of approximately 45 minutes, the ratios in Table 1 were followed.

Once the proper procedure for composite construction was identified, the procedure was standardized to ensure each test sample was constructed in the same fashion. The nominal fabrication time for each composite plate is shown in Table 2 . The plate section to be tested was $30.5 \mathrm{~cm} \times 30.5 \mathrm{~cm}$. Each plate was fabricated in the size of approximately $40 \mathrm{~cm} \times 40 \mathrm{~cm}$ so that the clamped boundary condition could be applied to the edge of the plate.

Strain gage rosettes with $45^{\circ}$ angles were attached to the composite plates on the opposite side to the impact. Since impact was applied to the top side of each plate, strain gages were attached to the bottom sides. Figure 2 shows the locations for four strain gage rosettes. No strain gage was attached to the center in order to observe the delamination occurring at that site.

Impact tests were conducted using a specially designed vertical drop weight testing system thoroughly described in Ref. [11, 13] and shown in Fig. 3, which consists of a drop weight impactor, load transducer, strain gages, high speed data analyzer,. The drop weight does not go into the water. Instead, a load transducer is located between the impactor and the composite specimen. By doing so, the impact condition becomes the same between the impact in air or under water. The force gage attached to one end of the load transducer was

Table 1 Resin and Additives Composition by volume

\begin{tabular}{lc} 
Component & Amount \\
\hline DERAKANE 510-A & $1000 \mathrm{~mL}$ \\
\hline Methyl Ethyl Ketone Peroxide (MEKP) & $12.5 \mathrm{~mL}$ \\
\hline Cobalt Napthenate (CoNAP) & $3.0 \mathrm{~mL}$ \\
\hline N, N- Dimethylaniline (DMA) & $0.5 \mathrm{~mL}$ \\
\hline
\end{tabular}

Table 2 Nominal fabrication time to make one laminated composite plate

\begin{tabular}{lc} 
Procedure & Time \\
\hline Lay-up (cutting and air evacuation) & $1-1.5 \mathrm{hrs}$ \\
\hline Chemical mixture & $10-15 \mathrm{~min}$ \\
\hline Resin Transfer & $15-20 \mathrm{~min}$ \\
\hline Post Cure (vacuum on - room temp) & $8 \mathrm{hrs}$ \\
\hline Post Cure (vacuum off - room temp) & $24 \mathrm{hrs}$ \\
\hline Post Cure (elevated temperature) & $6 \mathrm{hrs}$ \\
\hline TOTAL & Approx. $40 \mathrm{hrs}$ \\
\hline
\end{tabular}




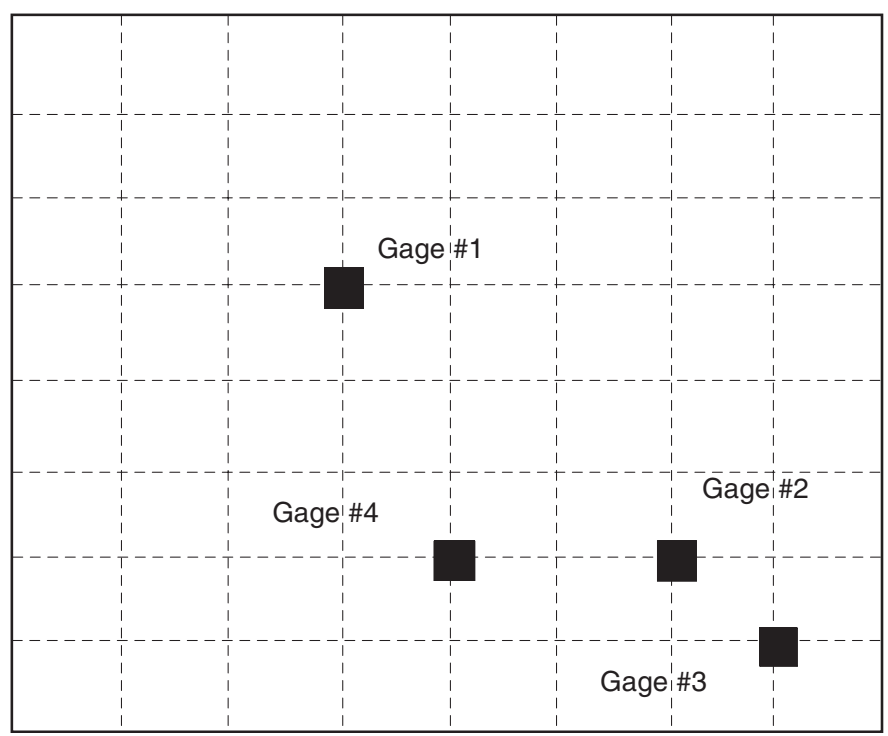

Figure 2 Locations of strain gage rosettes. Broken lines denote equal divisions of the test plate.

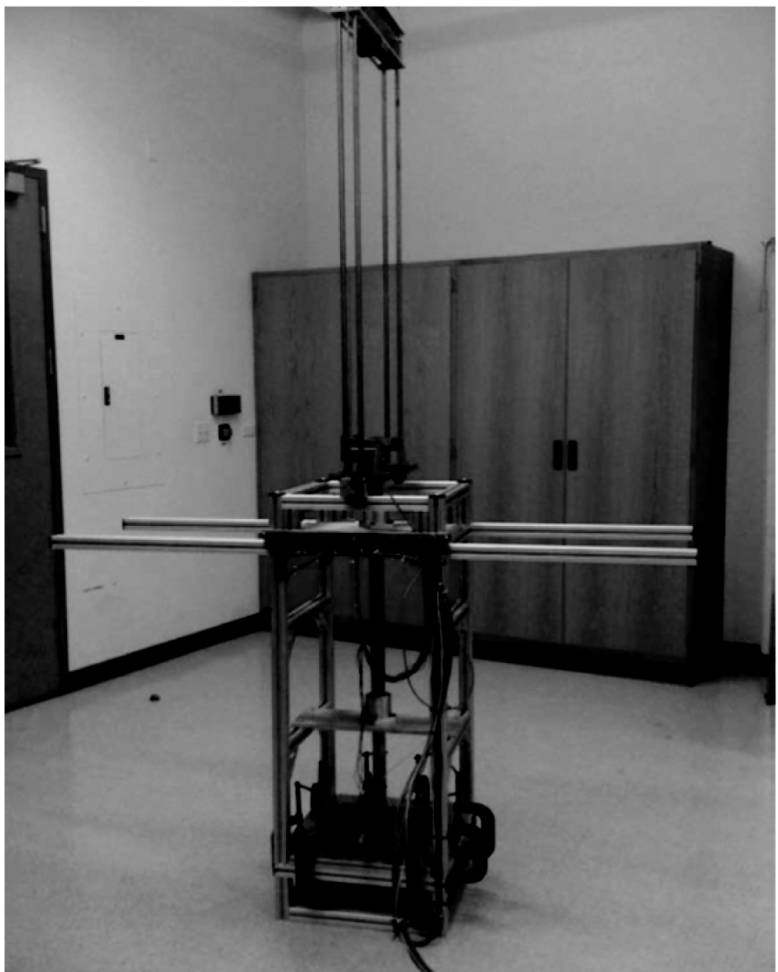

Figure 3 Impact testing machine. 
placed with a small distance away from the specimen in order to achieve greater throw and ensure specimen failure. A force gage with an axial connecter was fitted to the machine to prevent connector damage in the event that the force gage penetrated the specimen. The $7.6 \mathrm{~cm}$ C-clamps were used to facilitate clamped boundary conditions around the boundary of the test plate. Transient response of the composite plate was recorded using the force and strain gages.

During testing, the impact tower was lowered into an anechoic water tank that could be filled with water, so that the composite plate was submerged into water. Dry testing took place with the tower in the same position, but with the water drained out of the tank in order to maintain similar conditions between the two tests. The former is called wet impact while the latter is called dry impact, from now on. To avoid the moisture absorption into the composite plates, wet impact was conducted as soon as the plate was submerged into the anechoic water tank. The mass of the dropping object was $10.8 \mathrm{Kg}$ and the height was varied in a discrete increment to determine the initial damage and the damage growth.

\section{TEST RESULTS AND DISCUSSION}

Impact forces were measured as the drop-height increased for both dry and wet plates, respectively. The drop-height increased from $7.6 \mathrm{~cm}$ to $76.2 \mathrm{~cm}$ with an increment of $5.1 \mathrm{~cm}$. Figure 4 shows the force-time history plots for four different drop-heights. Figure 4(a)

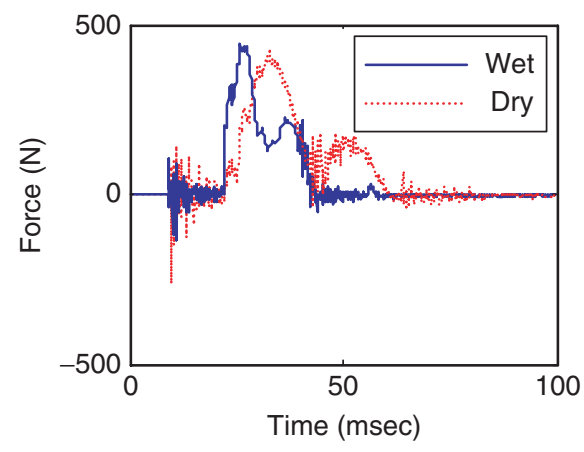

(a) Drop height: $7.6 \mathrm{~cm}$

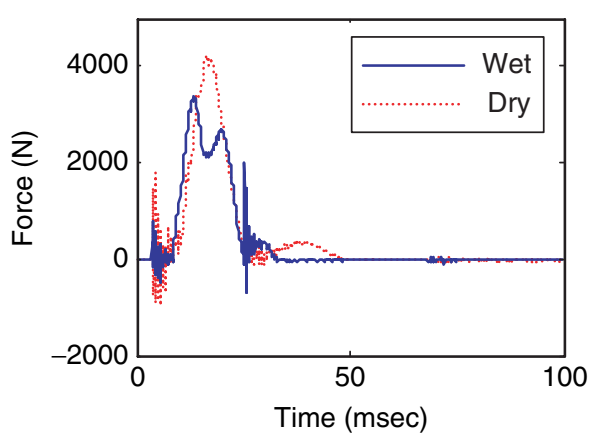

(c) Drop height: $61.0 \mathrm{~cm}$

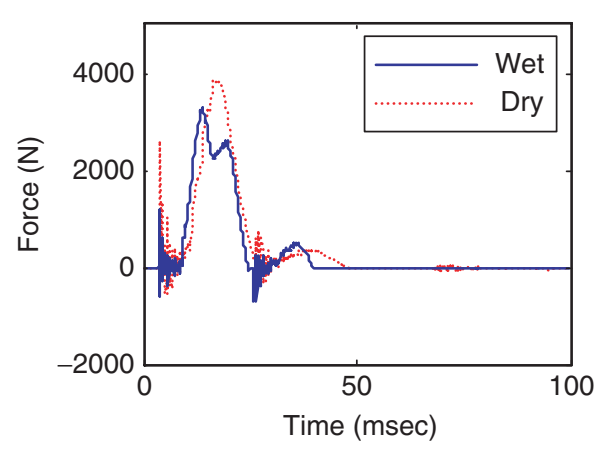

(b) Drop height: $55.9 \mathrm{~cm}$

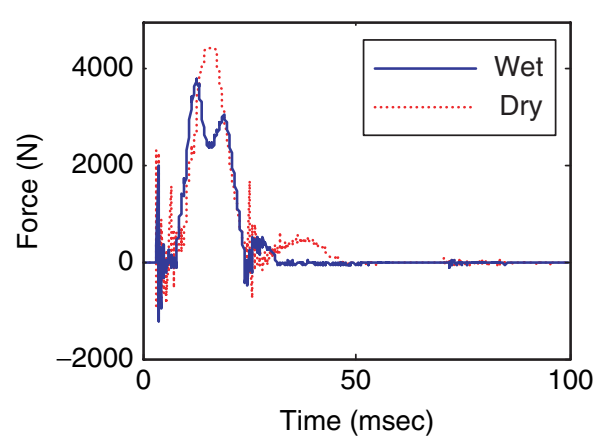

(d) Drop height: $71.1 \mathrm{~cm}$

Figure 4 Impact force-time history plots for impact loading with increasing drop-height. 
compares the wet and dry impact forces for the initial drop-height of $7.6 \mathrm{~cm}$ which does not yields any damage at all. Both dry and wet impacts resulted in almost the same magnitude of impact forces at the given drop height. Figure 4(b) is the force plot when initial damage occurred for the wet impact. On the other hand, Fig. 4(c) is the force plot when the dry impact caused initial damage. Finally, Fig. 4(c) plots forces after initial damage for both cases. While the magnitude of the impact forces increased along with the drop-height, the general shapes of the force-time curves remained the same. Figures 4 (b) through (d) show a larger force for the dry impact. This is because there was greater damage in the wet plate as shown in Fig. 5. The larger damage reduced the local stiffness of the impacted area, which resulted in a lower impact force.

In order to compare the impact forces between the wet and dry cases before damage, the same composite specimen was impacted for the two different impact conditions, dry and wet, respectively. By doing so, any potential variation from specimen to specimen could be eliminated. The result showed that impact force was greater for the wet impact when subjected to the same drop-height without damage. The difference between the wet and dry impact forces without damage became larger as the drop-height increased. This fact was also observed for other composite tests $[11,13]$. When the drop-height was low as shown in Fig. 4(a), the peak forces became more or less similar between the dry and wet impact. The reason for a larger impact force for the wet impact is the effect of added mass due to FSI. The added mass effect slows down the movement of the composite plate, which results in a larger contact force between the force gage and the specimen.

The major damage was the delamination which was in a circular shape. The diameter of the delaminated area was measured for each impact test, and the delamination size (i.e. diameter) was plotted against the measured peak impact force as shown in Fig. 5. This figure shows that wet impact results in delamination damage at a lower impact force. In other words, the damage is much larger for the wet impact when subjected to the same impact height. For the present tests, damage occurred with the peak impact force of $3200 \mathrm{~N}$ for the

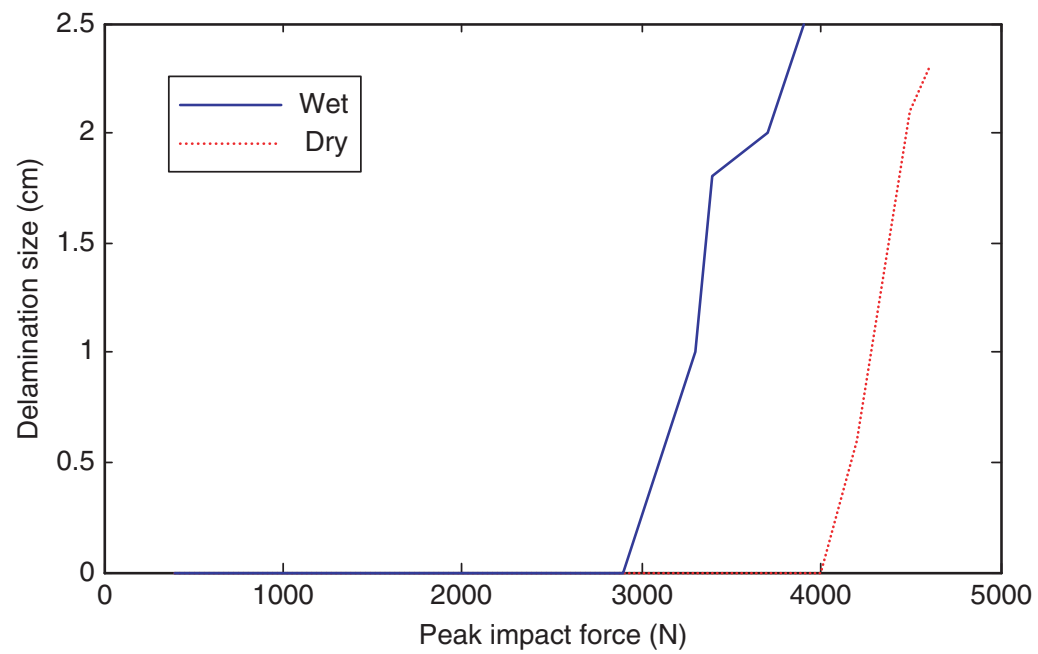

Figure 5 Plot of delamination sizes vs. peak impact forces for dry and wet impacts. 
wet impact and $4200 \mathrm{~N}$ for the dry impact. The damage initiation force for the wet impact was $76 \%$ of that for the dry impact.

Examination of strain-time history data revealed many interesting aspects. First of all, the difference of strain responses was not uniform over the composite plate surface between the wet and dry impact cases at the same drop-height which did not result in any damage. The difference was relatively small at some locations while it was huge at other locations. Generally, a location close to the center of the plate, where impacted, showed a less difference. Figure 6 shows the comparison of strains along the x-axis for dry and wet impact at four different gage locations when impacted with the drop-height of $10.2 \mathrm{~cm}$. Figure 6(a) shows a less difference in the overall shapes of the dry and wet impact strains at gage location \#1 which is closer to the impact site. The dry impact results in a larger strain than the wet impact as shown in Fig. 6(a). This is due to an unavoidable variation in two composite plates which were used for each impact test, respectively. When the same composite specimen was used for both dry and wet impact, respectively, the wet impact always resulted in a larger strain than the dry impact.

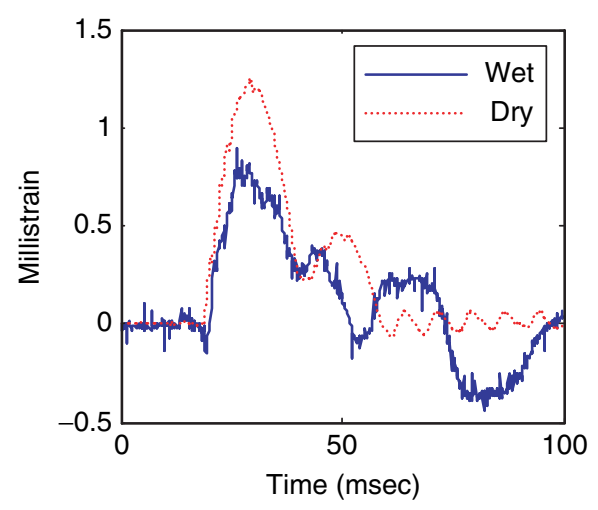

(a) Gage location \#1

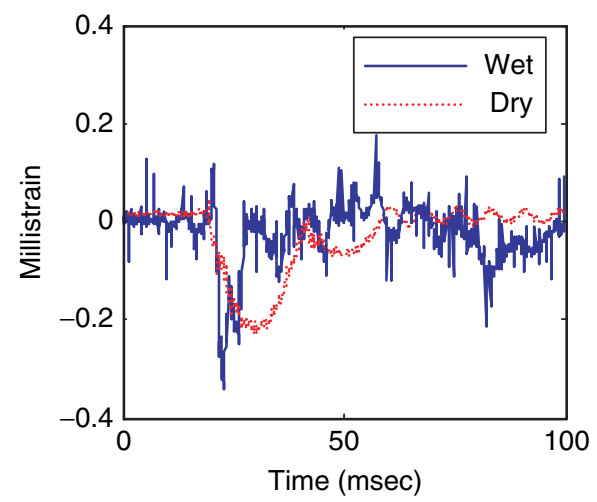

(c) Gage location \#3

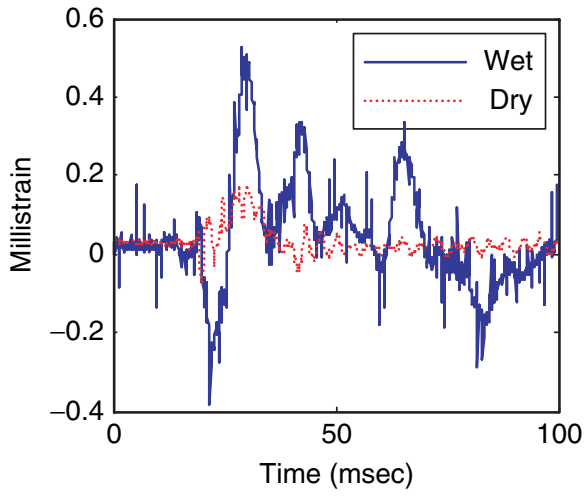

(b) Gage location \#2

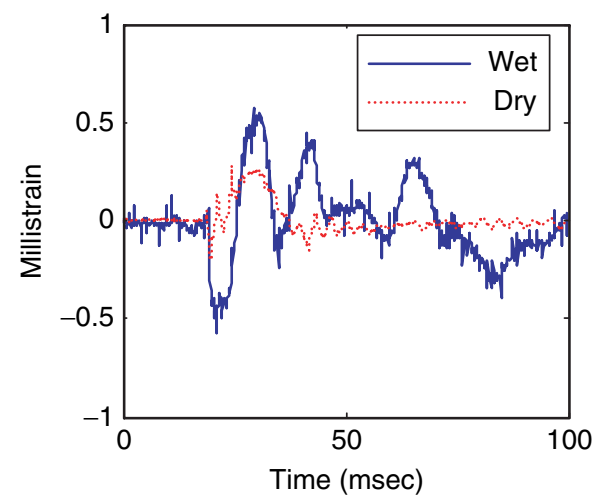

(d) Gage location \#4

Figure 6 Comparison of wet and dry impact $x$-strains at different locations of the plate when impacted from drop-height $10.2 \mathrm{~cm}$ (before damage). 
Gage location \#2 as seen in Fig 6(b) had the largest strain difference in terms of both magnitude and shape of the strain-time history. At this location, the strain due to wet impact is about three times greater than that resulting from dry impact. Additionally, the wet impact produces multiple peak and valleys while the dry impact yields one main peak. Furthermore, the former yielded initially negative peak strains followed by positive peak strains at gage locations \#2 and \#4 while the latter resulted in initially positive peak strains as shown in Fig. 6 (b) and (d). This suggests that the vibrational mode shape is different between the dry and wet impacts. Otherwise, both dry and wet impact should not yield two opposite signs of strains at those locations.

Figure 7 compares the strains along the y-axis at the same four different locations with the same drop-height as before. Woven fabric composite plates generally do not have the same material properties along the $\mathrm{x}$ - and $\mathrm{y}$-axis. Additionally, there are always some deviations from the ideal conditions such as the clamped boundary condition. As a result, strains at gage locations $\# 1, \# 2$, and \#3 are not the same. Comparing the strains in the $\mathrm{x}$ - and $\mathrm{y}$-axis shows

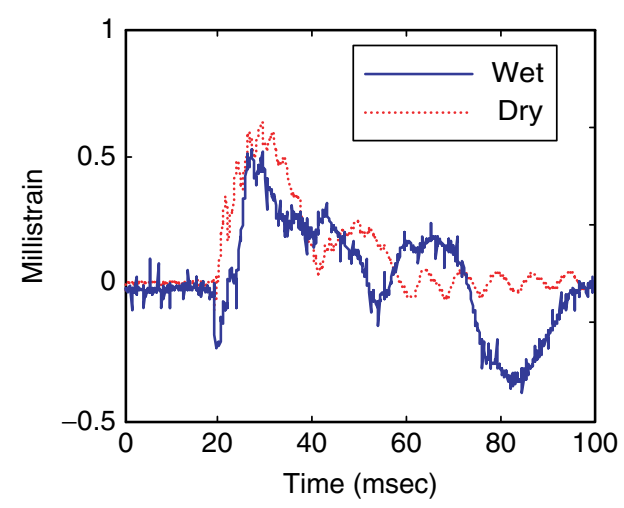

(a) Gage location \#1

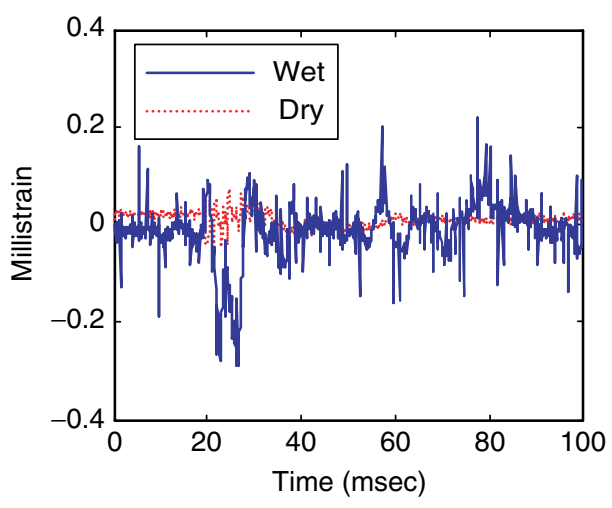

(c) Gage location \#3

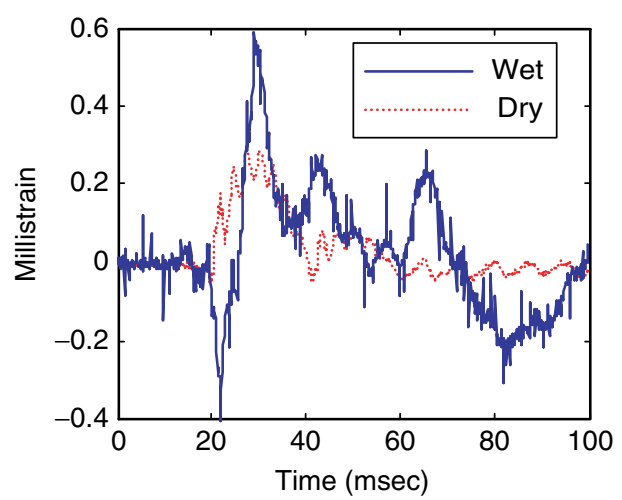

(b) Gage location \#2

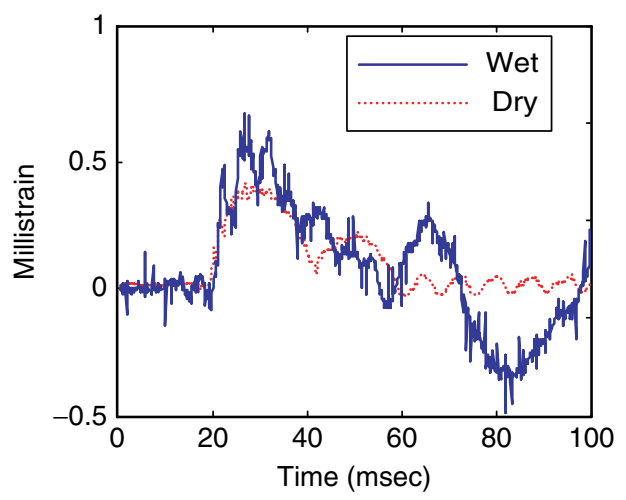

(d) Gage location \#4

Figure 7 Comparison of wet and dry impact y-strains at different locations of the plate when impacted from drop-height $10.2 \mathrm{~cm}$ (before damage). 
that the strain at gage \#1 yields a larger value along the $\mathrm{x}$-axis while their time-history shapes are very similar between the two axes. Strains at gage location $\# 2$ are very close in both axes. However, strains due to dry impact are quite different in both directions at gage location \#3. Additionally, Fig. 7 shows that the y-strains are relatively close between the dry and wet impact cases at gage locations \#1 and \#4. The strain magnitude is much higher for the wet impact at gage locations \#2 and \#3.

Figures 8 through 11 show the variation of the $\mathrm{x}$-strains at gage locations \#1 through \#4 as the damage progresses along with the increasing drop-height. Generally, strains for dry impact have relatively small variations in their transient behavior along with the damage evolution while those for wet impact have much larger changes with damage progression. The change in the transient strain response for the wet impact is especially significant during the early damage process as noted for drop heights of $55.9 \mathrm{~cm}$ and $61.0 \mathrm{~cm}$. This fact is clearly exhibited in Figs. 9 and 11. In those figures, $\mathrm{x}$-strains for the wet impact remain similar in terms of the shape of strain-time history between the drop-heights

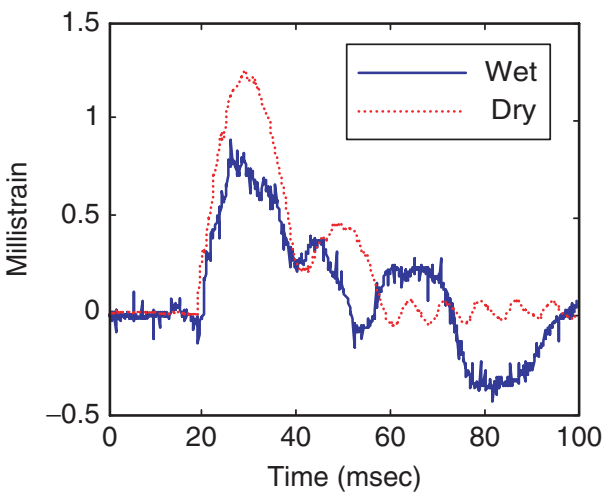

(a) Drop height: $55.9 \mathrm{~cm}$

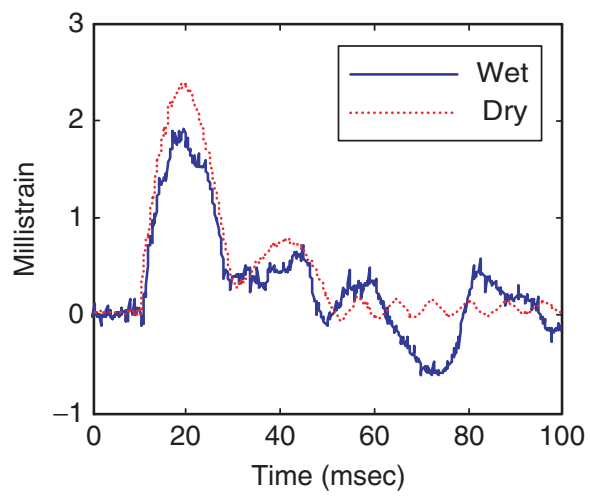

(c) Drop height: $71.1 \mathrm{~cm}$

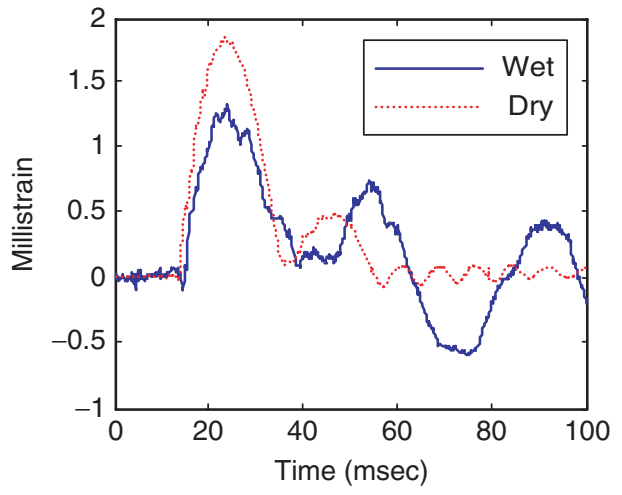

(b) Drop height: $61.0 \mathrm{~cm}$

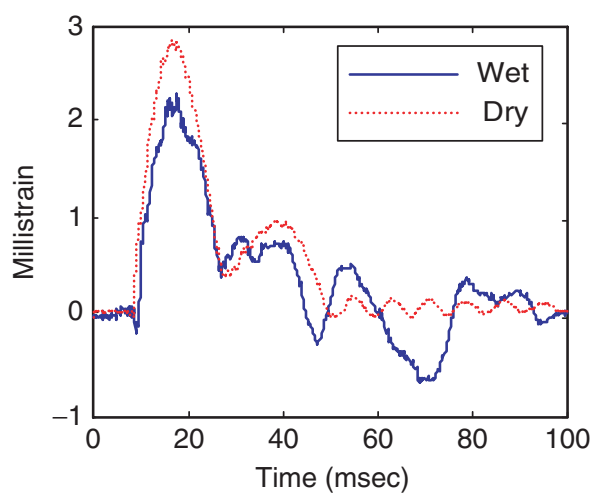

(d) Drop height: $76.2 \mathrm{~cm}$

Figure 8 Comparison of wet and dry impact $x$-strains at gage location \#1 with progressive damage. 


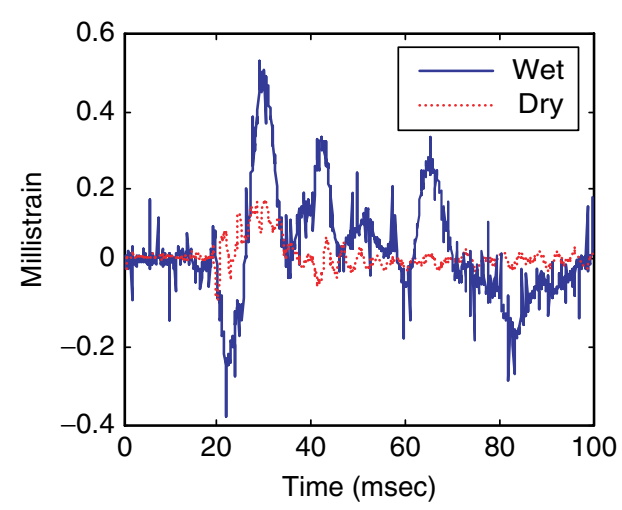

(a) Drop height: $55.9 \mathrm{~cm}$

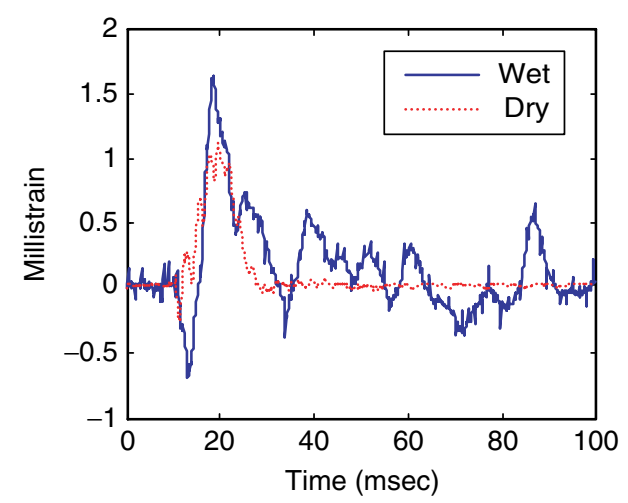

(c) Drop height: $71.1 \mathrm{~cm}$

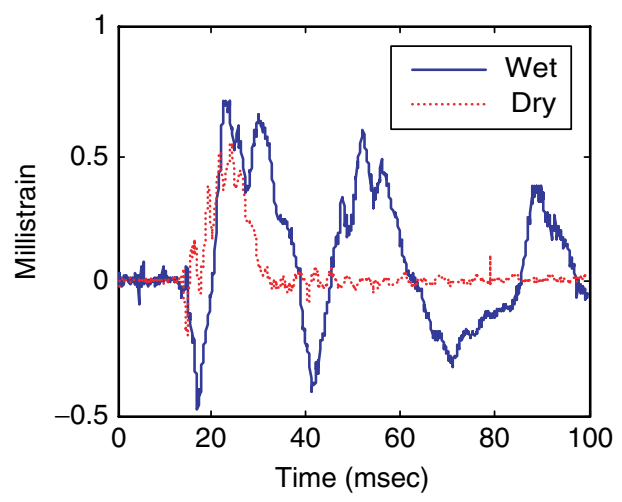

(b) Drop height: $61.0 \mathrm{~cm}$

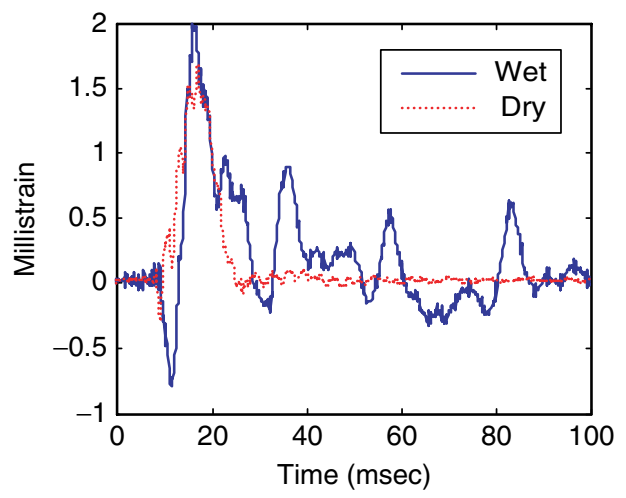

(d) Drop height: $76.2 \mathrm{~cm}$

Figure 9 Comparison of wet and dry impact $x$-strains at gage location \#2 with progressive damage.

$71.1 \mathrm{~cm}$ and $76.2 \mathrm{~cm}$. On the other hand, the $\mathrm{x}$-strain for wet impact at gage location \#3, near to a corner boundary, did not change much except an increase in its magnitude. The possible reason is that the point is the most remote from the damage section among all strain gage locations.

The strain along the y-axis at gage location \#4 is plotted in Fig. 12. At other locations, $y$-strains are similar, at least qualitatively, to x-strains so that they are not plotted here. The result in Fig. 12 follows the general descriptions described for the x-strain. However, one major difference observed in Fig. 12 is that the y-strains for the dry and wet impact have larger ratios of peak values along with the damage evolution. For example, the ratio for the drop-height of $55.9 \mathrm{~cm}$ is about 1.5 while that for the drop-height of $76.2 \mathrm{~cm}$ is greater than 2.0.

The added mass from FSI affected the frequency of the vibration as expected. The strain gage data were used to compute the vibrational frequencies. Table 3 lists the frequencies from two strain gage locations using both $\mathrm{x}$ - and $\mathrm{y}$-axis strains for dry and wet impact, 


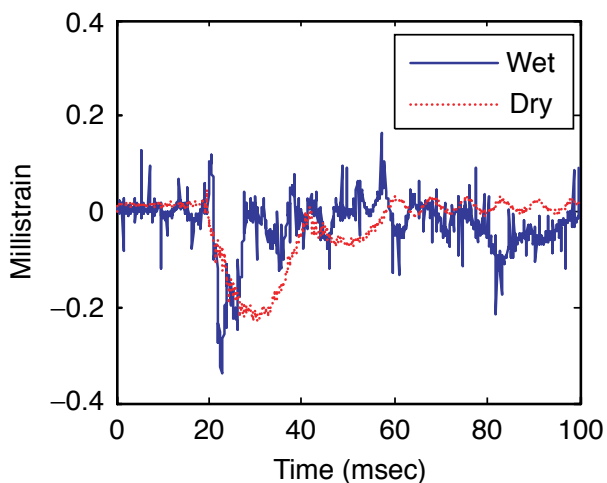

(a) Drop height : $55.9 \mathrm{~cm}$

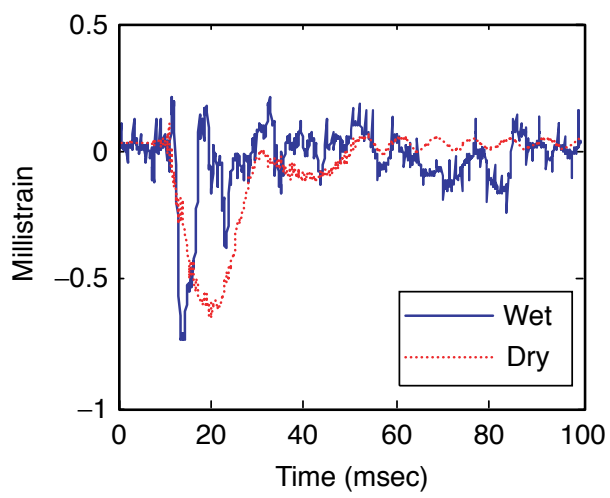

(c) Drop height : $71.1 \mathrm{~cm}$

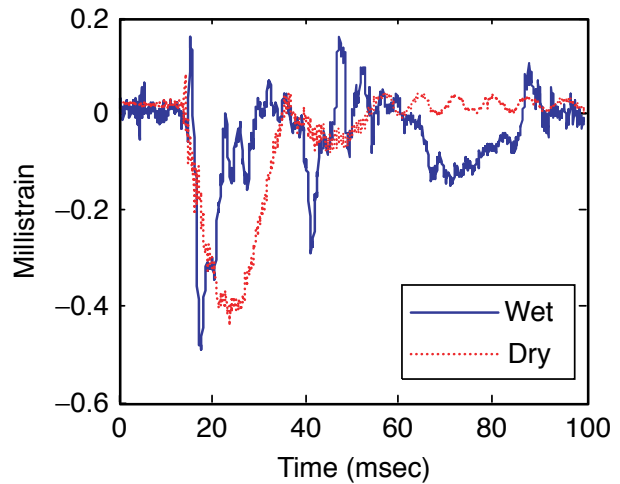

(b) Drop height : $61.0 \mathrm{~cm}$

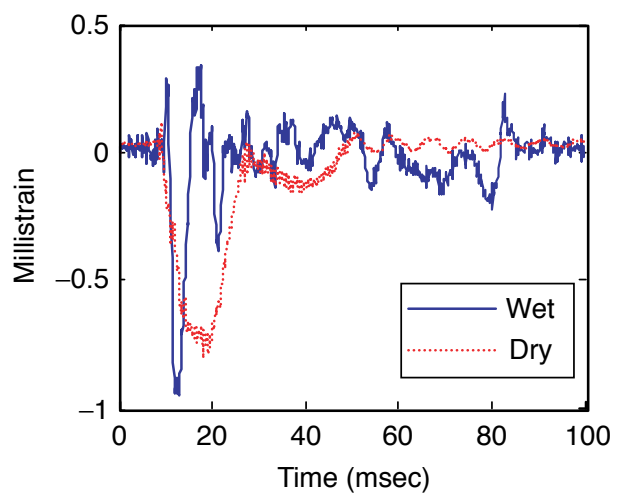

(d) Drop height : $76.2 \mathrm{~cm}$

Figure 10 Comparison of wet and dry impact $x$-strains at gage location \#3 with progressive damage.

respectively. From the frequency calculations, the Added Mass Factor (AMF), $\beta$ was calculated [15] using the following equation.

$$
\beta=\left(\frac{\omega_{d r y}}{\omega_{\text {wet }}}\right)^{2}-1
$$

where $\omega_{d r y}$ and $\omega_{\text {wet }}$ are the frequencies under dry and wet impact. The calculated AMF varied slightly from gage to gage because the FSI effect was different. The average value was about 9.5 which was similar to that for the clamped carbon composite plate [11] while the steel [15] had an AMF from 1.4 to 2.4 depending on the boundary conditions. This demonstrates again the strong FSI effect on polymer composites compared to steel. 


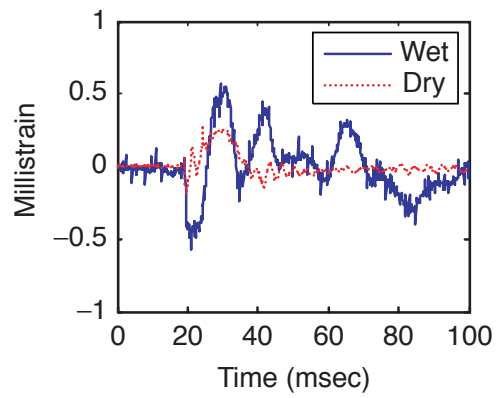

(a) Drop height : $55.9 \mathrm{~cm}$

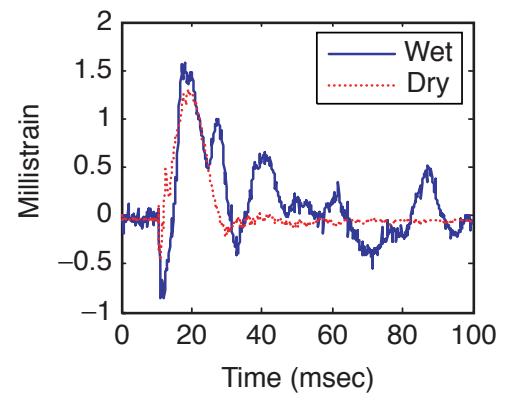

(c) Drop height : $71.1 \mathrm{~cm}$

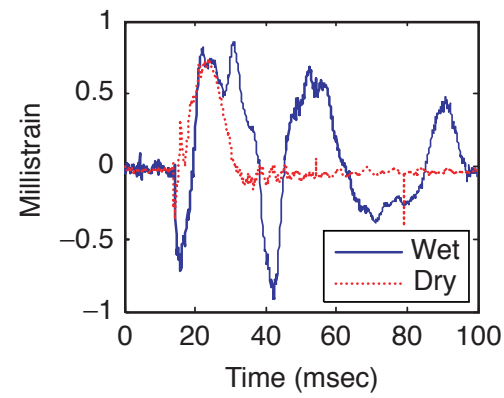

(b) Drop height : $61.0 \mathrm{~cm}$

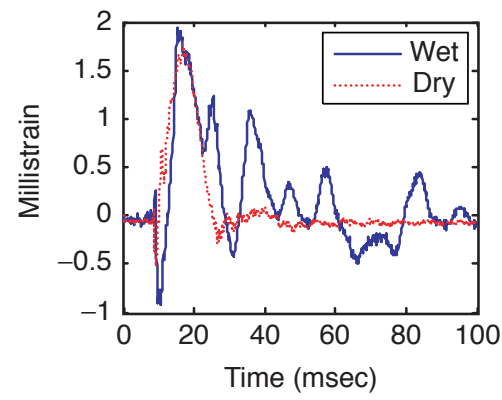

(d) Drop height : $76.2 \mathrm{~cm}$

Figure 11 Comparison of wet and dry impact $x$-strains at gage location \#4 with progressive damage.

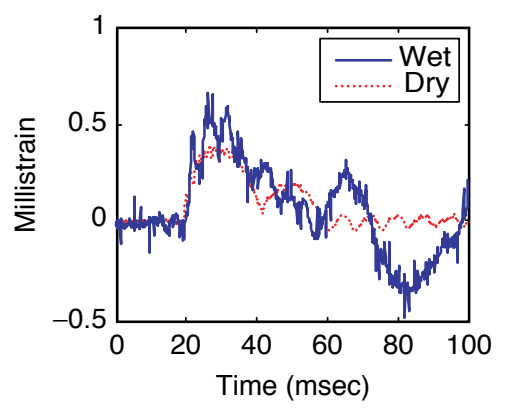

(a) Drop height: $55.9 \mathrm{~cm}$

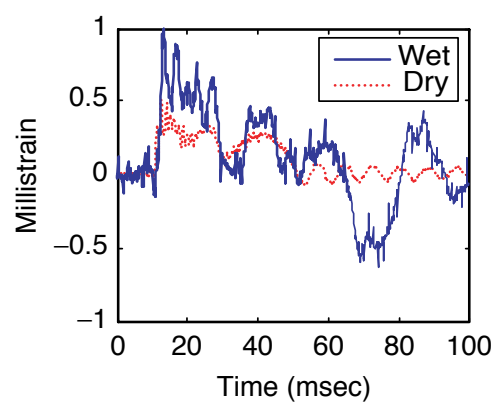

(c) Drop height: $71.1 \mathrm{~cm}$

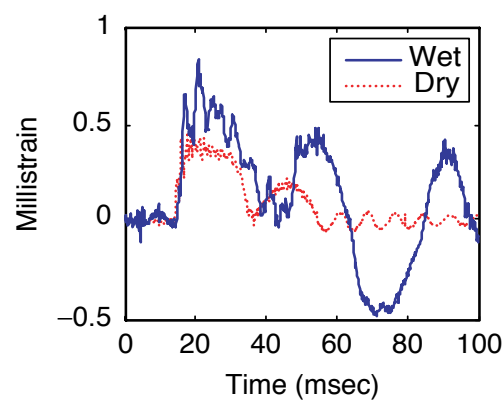

(b) Drop height: $61.0 \mathrm{~cm}$

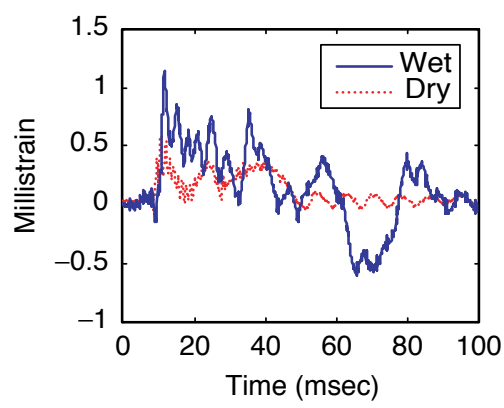

(d) Drop height: $76.2 \mathrm{~cm}$

Figure 12 Comparison of wet and dry impact y-strains at gage location \#4 with progressive damage. 
Table 3 Comparison of frequency ( $\mathrm{rad} / \mathrm{sec})$ between dry and wet impact

\begin{tabular}{|c|c|c|c|c|}
\hline & \multicolumn{2}{|c|}{ Dry impact } & \multicolumn{2}{|c|}{ Wet impact } \\
\hline & $\mathrm{X}$-axis & $y$-axis & $\mathrm{x}$-axis & y-axis \\
\hline Gage location \#3 & 532.5 & 637.2 & 180.0 & 180.0 \\
\hline Gage location \#5 & 573.8 & 634.7 & 184.3 & 190.4 \\
\hline
\end{tabular}

\section{CONCLUSIONS}

Experiments were conducted to investigate the transient dynamic response and progressive damage of laminated E-glass composite plates submerged in either water or air and subjected to impact loading. The study showed that the added mass effect of FSI has a significant influence on dynamic response as well as damage initiation and growth of the composite plate. The composite plate had damage initiation (i.e. delamination) at a lower drop-height when it was submerged in water as compared to in air. The wet impact resulted in greater damage than the dry impact for the same impact energy. In other words, the effect of FSI is detrimental to polymer composite structures because of the added mass effect. Additionally, the FSI effect was not uniform over the composite plate surface. Some locations showed a huge difference between the dry and wet impact responses of the strain-time history while other locations showed a less difference. The wet impact also produced a significant change in the transient time response of strains at some locations as damage grew while the dry impact did not. These results suggest that polymer composite structures for marine application in contact with water require a proper design and analysis including the FSI.

\section{REFERENCES}

[1] A.P. Mouritz, E. Gellert, P. Burchill, and K. Challis, "Review of Advanced Composite Structures for Naval Ships and Submarines," Composite Structures, Vol. 53, 2001, pp. 21-41.

[2] Z. Aslan, R. Karakuzu, and B. Okutan, "The Response of Laminated Composite Plates Under Low-Velocity Impact Loading," Composites Structures, Vol. 59, 2003, pp. 119-127.

[3] Y. W. Kwon and G. W. Wojcik, "Impact Study of Sandwich Composite Structures with Delamination," Journal of Composite Materials, Vol. 32, No. 5, 1998, pp. 407-430.

[4] S. Abrate, Impact Engineering of Composite Structures. Cambridge, (CISM Courses and Lectures, Vol. 526), printed in Italy, Springer, 2011.

[5] J. N. Baucom and M. A. Zikry, "Low Velocity Impact Damage Progression in Woven E-Glass Composite Systems," Composites Part A: Applied Science and Manufacturing, Vol. 36, No. 5, May 2005, pp. 658-664.

[6] R. A. W. Mines, C. M. Worrall, and A. G. Gibson, "Low Velocity Perforation Behaviour of Polymer Composite Sandwich Panels," Int. Journal of Impact Engineering, Vol. 21, Issue 10, Nov. 1998, pp. 855-879.

[7] Y. Fu, and W.G. Price, Interactions between a partially or totally immersed vibrating cantilever plate and the surrounding fluid, Journal of Sound and Vibration, Vol. 118, No. 3, 1987, pp. 495-513.

[8] M. K. Kwak, and K.C. Kim, "Axisymmetric Vibration of Circular Plates in Contact with Fluid," Journal of Sound and Vibration, Vol. 146, 1991, pp. 381-389.

[9] M. K. Kwak, "Hydroelastic Vibration Of Rectangular Plates," Journal of Applied Mechanics, Vol. 63, 1996, pp. 110-115.

[10] M.R. Haddara, and S. Cao, "A Study of The Dynamic Response of Submerged Rectangular Flat Plates," Marine Structures, Vol. 9, 1996, pp. 913-933. 
[11] Y. W. Kwon, A. C. Owens, A. S. Kwon, and J. M. Didoszak, "Experimental Study of Impact on Composite Plates with Fluid-Structure Interaction," Int. Journal of Multiphysics, Vol. 4, No. 3 , 2010, pp. 259-271.

[12] P. R. Hampson, and M. Moatamedi, "Fluid structure interaction of submerged metallic and composite plates subjected to low velocity impact loading," International Journal of Crash Worthiness, Vol. 15, February 2000, pp. 49-58.

[13] Y. W. Kwon, "Study of Fluid Effects on Dynamics of Composite Structures," ASME Journal of Pressure Vessel Technology, Vol. 133, June 2011, 031301-6.

[14] Y. W. Kwon and A. C. Owens, "Dynamic Responses of Composite Structures with FluidStructure Interaction,” Advances in Composite Materials, IN-TECH publisher, 2011.

[15] M.R. Haddara and S. Cao, "A Study of the Dynamic Response of Submerged Rectangular Flat Plates,” Marine Structures, Vol. 9, March 1996, pp. 913-933. 